\title{
Peran Peter William Hofland dalam Mengelola Tanah Partikelir Pamanoekan en Tjiasem Landen Subang Tahun 1802-1874
}

\author{
Pian Sopianna, Muhammad Noer Faturrachman, Mardani \\ Fakultas Adab dan Humaniora \\ UIN Sunan Gunung Djati Bandung \\ Email:piansop422@gmail.com
}

\begin{abstract}
This article deals with the role of a Peter William Hofland in developing the lands of Pamanoekan en Tjiasem in Subang Regency. William was considered to have successfully developed the lands, particularly in running the plantation business within the area of Subang. This study uses historical methods, namely heuristics, criticism, interpretation, historiography. Historically, William managed the land of Pamanoekan en Tjiasem since 1840 until his death in 1972. Within a period of 32 years, he had succeeded in developing the land of land in his territory namely Pamanoekan en Tjiasem Landen which is now known as Subang Regency.
\end{abstract}

Keywords: Land Policy, Peter William, Plantation Business 


\section{Pendahuluan}

Kabupten Subang masa penjajahan Belanda menjadi salah satu tanah penghasil kopi dan gula terbaik di Jawa, lewat manajemen dan pengeloaan yang baik oleh para pemilik-pemiliknya, Subang sendiri yang dulu dikenal yang dahulunya adalah perkebunan swasta atau tanah partikelir. Kemudian, pemilik kebun paling berpengaruh di tanah yang diberinama Pamanoekan en Tjiasem Landen adalah Peter William Hofland.

Perter William Hofland tidak terlalu dikenal dalam kancah sejarah Agraris. Dalam sejarah Agraris dikenal beberapa tokoh berpengaruh di daerah Jawa Barat, sebutsaja Karel Federick Holle banyak disebut dalam karya-karya sejarah di Indonesia bahkan banyak diteliti oleh peneliti asing, peneliti ini seperti Mikihiro Moriyama dalam bukunya Semangat Baru: Kolonialisme, Budaya Cetak, dan Kesastraan Sunda Abad ke-19 beberapakali menyinggung tokoh ini. Selain itu, peneliti Belanda Tom van den Berge menulis buku berjudul "Karel Frederik Holle: theeplanter in Indie 1829-1896" yang membahas tuntas tokoh tersebut. tidak kalah dari peneliti luar, Profesor Nina Herlina Lubis guru besar sejarah Universitas Padjajaran dalam desertasinya yang sudah dibukukan "Kehidupan Kaum Menak di Priangan" banyak juga membahas tokoh ini. Holle dikenal karena banyak menulis buku yang dihimpun dalam seri De Vriend van den Landman tentang pertanian yang juga diterjemahkan dalam berbagai bahasa daerah. Karya-karya Holle ini yang membuat beliau lebih dikenal publik khususnya para peneliti sejarah. Berbeda dengan Karel Federick Holle, Peter William Hofland tidak terlalu dikenal, namun kiprahnya dalam membangun perkebunan dan sifat pribadinya yang cinta masyarakat tidak kalah dari Karel Federick Holle. Dengan kecakapannya, P\&T Land menjadi salah satu perusahaan pertanian yang sukses. Terlepas dari itu penulis buku "Being "Dutch" in the Indies: A History of Creolisation and Empire, 1500-1920" Ulbe Bosma dan Remco Raben memberi julukan The Noble Landlord untuk Peter William Hofland, yang menjadi inspirasi ditulisnya buku Ups and Downs of Life in the Indies oleh Paul Adriaan Daum.

Dari sejarah nya itu P. W. Hofland menjadi tokoh yang mencolok dalam perkembangan agraris di kabupaten Subang, hal ini tentunya sangat penting untuk di teliti mengingat kontribusi dan perannya ini, dan peninggalan nya masih dapat di lihat sampai sekarang. 
Penulis ingin mencoba menggali biografi dan peran P. W. Hofland maka penulis membuat rumusanmasalah yaitu: 1 . Bagaimana biografi Peter William Hofland?, 2. Bagaimana peran P. W. Hofland dalam mengelola tanah P n T Land?, 3. Bagaimana dampak dan pengaruh P. W. Hofland bagi kabupaten Subang sekarang ini?. Dengan tujuan sebagai berikut : 1 . Mengetahui biografi Peter William Hofland, 2. Mengetahui peran P. W. Hofland dalam mengelola tanah P n T Land, 3. Bagaimana dampak dan pengaruh P. W. Hofland bagi kabupaten Subang sekarang ini.

\section{Metodologi}

Dalam melakukan penelitian ini, penulis menggunakan metode sejarah yang meliputi Heuristik, Kritik, Interpretasi, dan Historiografi. Dengan metode yang digunakan diharapkan dapat tercapai hasil penelitian yang berkualitas. Penelitian ini menggunakan pendekatan kualitatif atau apa adanya dan bersifat deskriptif. Adapun metode yang digunakan di uraikan dibawah ini.

Pertama, Heuristik yaitu pengumpulan sumber, dalam hal ini penulis mengandalkan studi literatur atau kajian pustaka sehingga sumber yang didapat berupa buku, jurnal baik didapat dari online ataupun dari beberapa perpustakaan. Diantaranya, Dinas Perpustakaan dan Kearsipan Jawa Barat, Perpustakaan UIN Sunan Gunung Djati Bandung, Dinas Pariwisata dan Budaya Kabupaten Subang, serta observasi ke lapangan khusunya di daerah bukanagara.

Kedua, kritik dilakukan untuk menguji kualitas sumber, dalam hal ini penulis melakukan pengjian dengan membuat perbandingan antara sumber satu dengan lainnya, hal ini dilakukan agar terujinya kualitas sumber yang digunakan, serta untuk membandingkan beberapa pendapat tentang Peter William Hofland ini.

Ketiga, Interpretasi yaitu tahap penafsiran, dengan membuat tinjauan teori, sebagai dasar dari penelitian. Keempat, Historiografi atau penulisan sejarah yang dilakukan dengan menyusun atau menulis fakta-fakta yang didapat secara sistematis.

Dalam hal ini penulis menggunakan teori orang besar sebagai cara untuk menjelaskan data yang ada, menurut Helius Syamsudin faktor utama dalam perkembangan sejarah adalah tokoh-tokoh besar sejarah merupakan 
biografi kolektif Adapun tokoh-tokoh besar itu adalah Kaisar, negarawan, Raja, panglima perang, jenderal dan para nabi. ${ }^{1}$

Jika dilihat dari teori di atas P. W. Hofland dapat digolongkan sebagai orang besar, karena dapat merubah keadaan suatu wilayah, beliau telah berhasil mengubah tanah partikulir $\mathrm{P}$ en $\mathrm{T}$ Land yang dulunya tidak produktif menjadi sangat produktif sampai bekas-bekas kejayaannya masih dapat dilihat sampai sekarang.

Dalam melakukan penelitian tentunya penulis juga membatasi permasalah yang ada dengan membuat batasan yaitu batasan Spasial dan Temporal. Penelitian ini terfokus meneliti daerah-daerah Pamanoekan en Tjiasem Landen sebagai tempat yang diperintah, atau dikelola Peter William Hofland yang sekarang menjadi daerah kabupaten Subang. Secara temporal penelitian mengambil waktu antara tahun 1840 sampai tahun 1872, alasan penulis mengambil rentang tahun tersebut karena pertamakalinya Peter William Hofland memiliki tanah-tanah Pamanoekan en Tjiasem Landen ini sekitar tahun 1840. Sedangkan tahun 1872 merupakan tahun meninggalnya Peter William Hofland.

\section{Hasil dan Pembahasan}

\section{Sejarah Pamanoekan en Tjiasem Landen}

Kabupaten Subang memiliki sejarah panjang khususnya dalam bidang agraris. pada masa pemerintahan Hindia Belanda, tepatnya pada masa awal pembukaannya, daerah Subang waktu itu P \& T Land merupakan tanah-tanah yang tidak produktif. Di kawasan ini tidak banyak produk yang dihasilkan. Komoditi yang ditanam penduduk berupa beras, kelapa, dan kopi. Penduduk juga memproduksi gula dan minuman yang diciptakan dengan metode yang sangat sederhana. Kemudian perusahaan $\mathrm{P} \& \mathrm{~T}$ kian berkembang saat Skelton mengambil alih tanah ini sampai tahun $1821 .^{2}$

Pada tahun 1830, kepemilikan tanah perusahaan $\mathrm{P}$ en $\mathrm{T}$ Land diambil alih oleh orang-orang berkebangsaan inggris. Pada masa inggris pengelolaan $\mathrm{P} \& \mathrm{~T}$ Land sudah mulai terorganisir. Pihak inggris membuat pengurus (manager) tapi hanya bertugas melakukan managemen keuangan di perusahaan P \& T Land, dengan melakukan penghematan anggaran secara

\footnotetext{
${ }^{1}$ Helius Sjamsuddin, Metodologi Sejarah (Yogyakarta: Ombak, 2007). 169

2 Miftahul Falah Iim Imadudin, Kunto Sofianto, "Gerakan Sosial Di Tanah Partikelir Pamanukan Dan Ciasem 1913," Patanjala: Jurnal Penelitian Sejarah Dan Budaya 4, no. 5 (2012). 436.
} 
ketat. Baru pada tahun 1839 perusahaan P \& T Land diambil alih lagi oleh pihak Belanda. ${ }^{3}$

Pada tahun 1840, J. Skelton menjual sisa saham atas tanahnya kepada Chr. Forbes, Micky Forbes dan J. Steward. Pada tahun 1842, pemilik baru tanah P \& T Land Chr. Forbes, Micky Forbes, dan J. Steward menjual sahamnya ke John Erich Banck, Thomas Benjamin Hofland, dan Peter William Hofland. Pada tahun 1848 bagian J. E. Banck ditransfer ke Th. B. Hofland dan P. W. Hofland. ${ }^{4}$

Kemudia pada tahun 1858, Peter William Hofland membeli saham P \& $\mathrm{T}$ Land yang dimiliki saudaranya. Oleh karena itu dia menjadi pemilik tunggal atas tanah-tanah P en T Land sampai ia meninggal di tahun $1873 .{ }^{5}$ Berkat P.W. Hofland tanah-tanah P en T Land menjadi produktif.

Setelah meninggalnya Hofland, sahamnya diberikan ke anak-anaknya namun tadak adanya kecakapan yang dimiliki anak-anaknya $\mathrm{P} \& \mathrm{~T}$ Land mengalami penurunan. Anak Hofland hidup dengan gaya mewah, karena itu tidak mengherankan bahwa setelah 1880 ketika harga Kopi turun drastis, situasinya menjadi semakin sulit. ${ }^{6}$

Pada tanggal 16 Desember 1886, P \& T berubah menjadi N.V. Maatschapij tot Eksploitative van de Pamanoekan en Tjiasemlanden. Padahal demikian, di kalangan penduduk masih konsisten disebut $\mathrm{P} \& \mathrm{~T}$. Dalam kurun waktu 32 tahun, dibawah pengelolaan Hofland itu, Perusahaan mendapat profit yang besar. Peter Wiliam Hofland merubah tanah-tanah terlantar menjadi perkebunan yang makmur dan teratur. Semenjak tahun 1920, tanah Pamanukan dan Ciasem berada di bawah kepemilikan AngloDutch Plantation of Java Limited sebelum akhirnya dinasionalisasi. Menurut data tahun 1867, tanah partikelir di kawasan Karesidenan Krawang terbagi atas 2 persil, ialah Ciasem dan Pamanukan dengan 8 distrik mencakup 325 desa, dan Tegalwaru dengan 4 distrik mencakup 49 desa. $^{7}$

\section{Biografi Peter William Hofland}

\footnotetext{
${ }^{3}$ Armin Asdi et al., Sejarah Kabupaten Subang (Subang: Dinas Pariwisata dan Kebudayaan Kabupaten Subang, 2007). 88.

${ }^{4}$ KITLV, "Short History of The Pamanoekan End Tjiasem Lands" (Amsterdam, n.d.). h.3.

${ }^{5}$ KITLV. h.5, Lihat Juga Armin Asdi, 2007. h.87.

${ }^{6}$ KITLV. h.5.

${ }^{7}$ Iim Imadudin, Kunto Sofianto, "Gerakan Sosial Di Tanah Partikelir Pamanukan Dan Ciasem 1913.” h.436.
} 
Peter William Hofland di lahirkan di Madras India pada tanggal 07 September 1802 adalah keturunan Belanda dari ayahnya sedang ibunya merupakan keturunan India yang berasal dari kota Jegernekpoeram India, beliau juga menikah dengan istrinya yang juga dari keturunan India. Kemudian, beliau dikaruniai dua orang anak yang pertama diberi nama Yohanues Theodous Hofland yang kemudian anaknya ini tinggal di Surabaya, anak nya yang kedua di beri nama Egbert Charles Hofland yang kemudian tinggal di daerah Bogor. ${ }^{8}$

Di tahun 1830 ia sampai di Indonesia dan berlabuh di pelabuhan Pasuruan Jawa Timur. Pada awalnya ia menjadi saudagar kopi sebagai profesi utamanya di tahun 1833, kemudian ia bekerja sama dengan pemerintah Hindia Belanda dalam hal perdagangan kopi. Dan pada tahun 1840 turut menjadi pemilik (made eigenaarl) Tanah Pamanoekan en Tjiasem Landen bersama saudara nya bernama Th.B Hofland. Di tahun 1858 membeli seluruh saham saudaranya dan menjadi pemilik tunggal tanah tersebut.

Sebagai pemegang saham terbesar pada tahun 1854 menurut peraturan pemerintah (reggering reglement) ia sebagai pemegang perintah di wilayah nya yaitu pamanoekan en Tjiasem Landen yaitu untuk mengangkat pejabat pemerintah yaitu demang yang dikepalai oleh seorang Hoofd Demang Martabat Kartadikarga.

Di usianya yang ke 48 tahun P. W. Hofland mendirikan P n T Land berdasrkan sistem VOC dan sistem yang berhubungan dengan sistem perdagangan yang diterapkan kerajaan inggris.

Peter William Hofland meninggal pada 4 Februari 1872, dengan warisan Tanah Pamanoekan en Tjisem Landen yang kemudian di wariskan kepada anak pertamanya Yohanes sebelum nantinya berpindah tangan ke pihak lain.

\section{Peran P. W. Hofland dalam Mengembangkan Tanah P n T Landen Subang}

\section{Membangun Infrastruktur}

Menurut Ubel Bosma dan Remco Raben, Hofland pergi ke Jawa bersama dengan saudaranya Thomas Benjamin. Berkat koneksi yang baik,

${ }^{8}$ Joko Dwi Avianto, "Patung Cagar Budaya p.w. Hofland: Sebuah Telisik Warisan Seni Patung Eropa Di Kabupaten Subang," Isbi Bandung, n.d. 
saudara-saudara berhasil mengantongi kontrak dalam bisnis gula, dan pada tahun 1840 mereka telah memperoleh cukup uang untuk mengambil alih properti luas pemilik Inggris, yang tidak melihat untung dalam mengembangkan tanah itu. Tokoh Rotterdam, Anthony van Hobaken, bertindak sebagai perantara dalam pengambilalihan tersebut, ketika ia memberi tahu NHM (Perusahaan Perdagangan Belanda), agar tanah yang luas ini dibawa ke "tangan-tangan yang lebih nasional, Hofland berubah menjadi tuan tanah teladan dan baik hati" Dia membuka pasar di mana para penduduk lokal dapat membeli pakaian dengan harga murah, dan ia mendirikan sekolah-sekolah di mana anak-anak dapat belajar aritmatika dasar dan bahasa Melayu. Tindakannya yang paling bermanfaat adalah mengurangi tingkat pengeluaran keluarga bagi ribuan petani yang hidup di tanahnya, padahal dia diwajibkan untuk melakukan ini, sesuai dengan putusan mengenai perkebunan pribadi. Seperti Janti, ketika dia melakukan tur perkebunannya, Hofland disertai oleh seorang penjaga kehormatan. " Reputasinya sebagai tuan tuan besar (raja agung) bertahan selama beberapa generasi di antara penduduk setempat. ${ }^{9}$

Menurut Ten Brink Hofland dengan membuka pasar dia juga memastikan bahwa kain pakaian yang ditawarkan "dengan harga serendah mungkin. Ten Brink, yang menyebut perdagangan Belanda" tanpa pamrih " dapat dianggap sebagai perwakilan dari" imperialisme humanistik, " Hofland juga suka menaikkan upah dari upah harian biasanya, sehingga mereka dapat membayar harga produk atau membiarkan pemerintah Belanda dapat mengatur pasar kain. ${ }^{10}$

Selain pasar dan sekolah ia juga membagun jalur-jalur transfortasi dengan membagun jembatan dan jalan-jalan untuk distribusi hasil perkebunan, dibeberapa tempat masih ditemukan jalur-jalur kereta kecil untuk menggangkut tebu. ${ }^{11}$

\section{Membentuk Kedemangan}

${ }^{9}$ Ulbe Bosma and Remco Raben, Being "Dutch" in the Indies: A History of Creolisation and Empire, 1500-1920 (Singapura: NUS Press, 2008). 127-128

${ }^{10}$ Jan Ten Brink, Op de Grenzen Der Preanger: Reisschetsen En Mijmeringen (Batavia: Van Dorp, 1861). 83

${ }^{11}$ Iim Imadudin, "DAMPAK KAPITALISME PERKEBUNAN TERHADAP PERUBAHAN KEBUDAYAAN MASYARAKAT DI KAWASAN SUBANG 1920-1930,” Patanjala : Jurnal Penelitian Sejarah Dan Budaya 6, no. 1 (2014). 
Dalam buku sejarah Kabupaten Subang P. W. Hofland juga berperan dalam menata pemerintahan di Kabupaten Subang untuk mengatur ketertiban daerahnya tersebut supaya tanah yang digarap nya atau pengeksploitasian atas tanah miliknya itu dapat berjalan dengan intensif. Bersandar kepada RR tahun 334 yaitu setelah mengangkat beberapa orang Indonesia untuk dijadikan sebagai Demang, tugasnya sendiri menyelenggarakan pemerintah di daerah daerah. Demang dibantu tugasnya oleh para Asisten Demang, Patih, Menteri, juru taksir, umbul, upas, Sebagai pemegang hukum juga ada jaksa.

Mengingat pada waktu itu pemilik tanah partikelir memiliki hak eigenom hak khusus untuk mengatur wilayahnya sendiri dengan kebijakan itu Hofland dapat dengan mudah mengatur wilayanya.

Di daerahnya sendiri terbagi menjadi 8 Demang, yaitu:

a. Demangan batu sirap di Batu sirap yang kemudian kedudukan Demang pindah ke Cisalak

b. Kademangan Sagalaherang di Sagalaherang

c. Kademangan Ciherang di Ciherang

d. Kademangan Pagaden di Pagaden.

e. Kademangan Pamanukan di Pamanukan

f. Kademangan Ciasem di Ciasem

g. Kedemangan Malang di Purwadadi

h. Kademangan Kalijati di Kalijati

Para Demang ini diusulkan oleh pemilik tanah kepada pemerintah untuk diangkat oleh Gubernur Jenderal Berdasarkan Keputusan Jenderal tanggal 18 Agustus 1859 dapat diketahui bahwa Raden Tanu Diraja telah menjadi Demang Ciherang. ${ }^{12}$

\section{Membuat Pondasi Cikal Bakal Kota Subang}

Diperkirakan bahwa tahun 1850 P. W. Hofland memilih kedemangan Ciherang sebagai kediamannya. tempat tersebut diperkirakan terletak di sebelah utara lapangan golf atau yang sekarang menjadi alun-alun Subang. Di Ciherang Hofland membangun gedung untuk perkantoran tempat administrasi perkebunannya, rumah-rumah pegawai, gedung tersebut pada

${ }^{12}$ Armin Asdi et al., Sejarah Kabupaten Subang (Subang: Dinas Pariwisata dan Kebudayaan Kabupaten Subang, 2007). 37 
waktu itu dinamakan gedung gede, gedung terkenal sampai saat ini adalah wisma karya dipusat kota Subang saat ini.

Gagasan awal dipilihnya kedemangan Ciherang sebagai tempat karena daerah tersebut terletak di tengah-tengah mempermudah pengawasan daerah-daerah lainnya. Sekitar tahun 1850 di tempatnya tersebut masih jarang penduduk itu lalu ia membuat perusahaan tebu untuk menarik pekerja dari luar, benar saja karena kekurangan pekerja maka didatangkanlah buruh dari daerah-daerah lain seperti Cirebon, Majalengka, Rajagaluh, dan Kuningan. disitu kemudian mendirikan rumah-rumah atau yang disebut Babakan di setiap pabrik penggilingan tebu mereka mendirikan Babakan tersebut dan diberi nama Babakan Subang, lambat laun tempat itu berkembang menjadi sangat ramai kemudian menjadi Kota Subang saat ini dan sekaligus pusat pemerintahan. ${ }^{13}$

\section{Mengembangkan Perkebunan}

Sebagaiman disebutlkan di atas di $\mathrm{P}$ en $\mathrm{T}$ land awalnya merupakan tanahtanah yang tidak produktif dan kurang menguntungkan namun dimasa $\mathrm{P}$. W. Hofland hal itu terbalik 180 derajat menjadi salah satu darah yang paling produktif di Jawa, bahkan di elu-elukan oleh Jan Ten Brink seorang penulis Inggris yang membuat tulisan tentang Priangan.

Dalam segi Pengelolaan tanah pemilik memiliki dua macam sistem yang pertama, yang langsung diusahakan oleh pembeli tanah tanah-tanah itu langsung dirawat dijadikan sawah ladang dan perkampungan penduduk biasanya diurus oleh para Demang memiliki tugas sebagai pengatur atau pemerintah berwenang. kedua yaitu bagian yang langsung diusahakan oleh pemilik tanah dalam bentuk perkebunan perkebunan di sini dipimpin oleh seorang administrator, administrator ini bertanggung jawab kepada pemilik tanah. Perkebunan-perkebunan ini nantinya menghasilkan mantan aman untuk diekspor ke luar negeri.

Dengan dilaksanakannya culture stelsel, pemerintah memberikan tanaman-tanaman baru didatangkan langsung dari luar negeri untuk memperbaiki tanaman yang sudah ada ih arti teh pohon palem minyak tembakau singkong Kina dan karet sebelumnya telah diuji coba di Kebun Raya Bogor langsung oleh Reinwardt. perkebunan perkebunan di daerah Pamanukan and Tjiasem Land Tuga mengusahakan tanaman-tanaman baru

${ }^{13}$ Asdi et al. 39 
untuk diekspor ke luar negeri bahkan tanaman karet yang pertama dilakukan di perkebunan punan ini dan ditanam pada tahun 1864 itu juga ditanam teh kopi kina dan lain-lain. ${ }^{14}$

Tabel: Sebaran daerah Pamanoekan en Tjiasem Landen

\begin{tabular}{|l|l|l|l|l|l|l|l|}
\hline No & Daerah & $\begin{array}{l}\text { Nama } \\
\text { perkebunan }\end{array}$ & Teh & Kopi & Karet & Kina & $\begin{array}{l}\text { Lain- } \\
\text { lain }\end{array}$ \\
\hline 1 & Batusirap & Bukanagara & X & X & - & X & X \\
& & Kasomalang & - & X & - & - & - \\
& & Sarireja & X & X & X & - & - \\
& & Ciater & X & - & - & X & - \\
& & Jagurnaik & - & - & - & - & X \\
\hline 2 & Sagalaherang & Serangsari & X & X & X & - & - \\
\hline 3 & Subang & Cipeo & X & X & X & - & - \\
\hline 4 & Kalijati & Wangunreja & - & X & X & - & - \\
\hline 5 & Purwadadi & Pasirbungur & - & X & X & - & - \\
\hline & & Pasirmuncang & - & X & X & - & - \\
\hline
\end{tabular}

Sumber: Armin Asdi et al., Sejarah Kabupaten Subang (Subang: Dinas Pariwisata dan Kebudayaan Kabupaten Subang, 2007)

\section{Kesimpulan}

Dari pembahasan diatas kita dapat mengambil kesimpulan bahwa tanah-tanah di Pamanoekan en Tjiasem Landen pada masa Peter William Hofland menuju titik yang gemilang terbukti dengan capaiannya yang dinilai baik bagi kemajuan daerah tersebut, diantara capaiannya dibidang sosial dan ekonomi masyarakat ia telah membangun pasar dan sekolah untuk pribumi, selain itu harga yang dipatoknya lebih murah dari pedagang cina. Kedua, capaiaannya dibidang pemerintahan dan politik membentuk kedemang yang dapat mengelola wilayahnnya dengan efektif. Ketiga, dalam hal infrastruktur beliau telah berperan besar dalam membangun kota Subang, gedung-gedung penting yang ada di kota Subang seperti Alun-alun, Wisma karya, dll adalah hasil usahannya. Keempat, dalam hal pengelolaan tanah beliau telah berhasil

\footnotetext{
${ }^{14}$ Asdi et al. 40
} 
Peran Peter William Hofland dalam Mengelola Tanah Partikelir Pamanoekan en Tjiasem Landen Subang Tahun 1802-1874| Pian Sopianna, dkk

menanam komoditi unggulan yang sisa-sisa kebunnya masih ada sampai sekarang.

Dari beberapa kesimpulan diatas kita bisa menilai bahwa Peter William Hofland berperan besar dalam pembentukan wilayah Subang saat ini. 
Peran Peter William Hofland dalam Mengelola Tanah Partikelir Pamanoekan en

Tjiasem Landen Subang Tahun 1802-1874| Pian Sopianna, dkk

\section{Daftar Rujukan}

Asdi, Armin, Adit Supardi Mardiana, Hitnes Surwijaya, and Muhammad Natsir Adisaputra. Sejarah Kabupaten Subang. Subang: Dinas Pariwisata dan Kebudayaan Kabupaten Subang, 2007.

Avianto, Joko Dwi. "Patung Cagar Budaya p.w. Hofland: Sebuah Telisik Warisan Seni Patung Eropa Di Kabupaten Subang.” Isbi Bandung, n.d.

Bosma, Ulbe, and Remco Raben. Being "Dutch" in the Indies: A History of Creolisation and Empire, 1500-1920. Singapura: NUS Press, 2008.

Brink, Jan Ten. Op de Grenzen Der Preanger: Reisschetsen En Mijmeringen. Batavia: Van Dorp, 1861.

Iim Imadudin, Kunto Sofianto, Miftahul Falah. "GERAKAN SOSIAL DI TANAH PARTIKELIR PAMANUKAN DAN CIASEM 1913.”

Patanjala: Jurnal Penelitian Sejarah Dan Budaya 4, no. 5 (2012).

Imadudin, Iim. "DAMPAK KAPITALISME PERKEBUNAN TERHADAP PERUBAHAN KEBUDAYAAN MASYARAKAT DI KAWASAN SUBANG 1920-1930." Patanjala: Jurnal Penelitian Sejarah Dan Budaya 6, no. 1 (2014).

Sjamsuddin, Helius. Metodologi Sejarah. Yogyakarta: Ombak, 2007. 